\title{
Research on defects and control method based on thread shaft forming
}

\author{
Huajun Yan ${ }^{1,2, a}$, Shuangjie Zhang ${ }^{1,2, b}$, Shibo $\mathrm{Ma}^{1,2, \mathrm{c}}$ \\ ${ }^{1}$ School of Materials Science and Engineering, Hebei University of Science and Technology, \\ Shijiazhuang 050018, China \\ ${ }^{2}$ Key Laboratory of Material Near-net Forming Technology, Shijiazhuang 050018, China \\ aemail: yanhj22@163.com, bemail: zsjzlili@163.com, email:mashibo1980@163.com
}

Keywords: cross wedge rolling; thread shaft; pitch; tooth height

\begin{abstract}
The defects of incomplete tooth, low tooth height and big pitch are easy to produce, when the thread shaft is rolled by cross wedge rolling. The forming defects of teeth are researched by theoretical analysis and numerical simulation, the causes of producing tooth defects are analyzed, and forming process is researched by optimizing the die structure. The open structure of the die is designed as the closed structure on the end of the thread tooth. In addition, the tooth width of the die is optimized from equal width mode to variable width mode. Thus higher quality teeth are obtained and tooth defects are eliminated. The research results have a good reference for accurately forming thread shaft.
\end{abstract}

\section{Introduction}

Because of the complex teeth structure, large modulus thread shaft is generally used to transfer space power. Most large modulus thread shafts are cut by turning or milling, whirling milling is especially a efficient method of machining thread shaft, which is usually rebuilt by installing milling device in the ordinary lathe. Whirling milling can process the worm that is the special thread shaft from 20 to $200 \mathrm{~mm}$ diameter, and surface roughness of the workpiece is up to Ra1.6 to $3.2 \mathrm{~mm}$. Cutting process is a lower material utilization cutting method, in which the workpiece is produced by cutting excess metal. At present the industry is facing energy shortage, environmental pollution and other problems, so the advanced manufacturing technology with the characteristics of saving energy and protecting environment is the development direction of the industry[1]. The cross wedge rolling is the advanced manufacturing technology with advantages of saving materials, high efficiency and protecting environment[2][3]. Many experts and scholars have conducted in-depth research for the technology and gained valuable research results[4][5][6], and many technology of rolling shafts are applied to the industrial production[7][8]. In summary, rolling thread shaft by cross wedge rolling has good prospect. This paper will analyze the defects when thread shaft is formed and the causes of defects, and propose solutions for controlling the defects. The research results have important guiding significance for precise rolling thread shaft.

\section{parameters of the threaded shaft}

The thread shaft with trapezoidal cross section shown in Figure 1 is the research object, and the parameter values of the thread shaft are shown in Table 1 . The forming defects of teeth and the causes of producing defects are analyzed by the theoretical analysis and the finite element method. By analyzing the plastic deformation of the rolled part and the tooth structure of the die and other factors, the solution of tooth defects is found. 


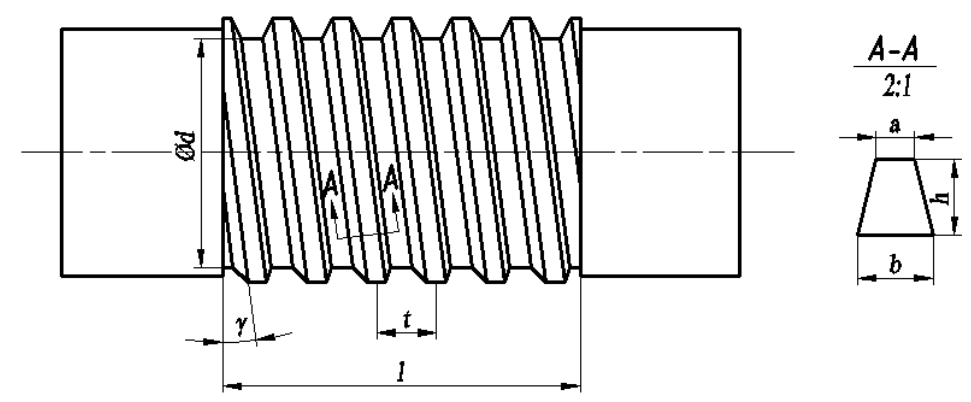

Fig.1. Thread shaft

Table 1 Parameters of the thread shaft

\begin{tabular}{ccccccc}
\hline$d / \mathrm{mm}$ & $l / \mathrm{mm}$ & $\gamma /\left(^{\circ}\right)$ & $t / \mathrm{mm}$ & $a / \mathrm{mm}$ & $b / \mathrm{mm}$ & $h / \mathrm{mm}$ \\
\hline 43.2 & 70.8 & 4.87 & 11.8 & 3.0 & 7.5 & 8.0 \\
\hline
\end{tabular}

\section{Forming mechanism of tooth defects}

The tooth forming principle of trapezoidal thread shaft is shown in Figure 3, and the initial stage and end stage for thread forming are respectively shown in Figure 3(a) and Figure 3 (b). In Figure 3 (a), the top surfaces of $A B$ and $C D$ contact with the outer contour LL of the blank in the initial forming stage, in which the blank does not produce plastic deformation. The center distance of the die and the roller part is fixed value, and the tooth height of the die gradually becomes higher, so the teeth of the die gradually push the part of metal into the internal rolled part, which forms gullets in the part and the extruded metal flows into the internal gullet cavity of the die. In Figure 3(b), the extruded metal EABI flows into IJMN and EFGH, all of the teeth of the die simultaneously squeeze the part, and finally all the extrusion of metal fill into the entire die gullet, which forms complete teeth, such as the tooth BJKC.

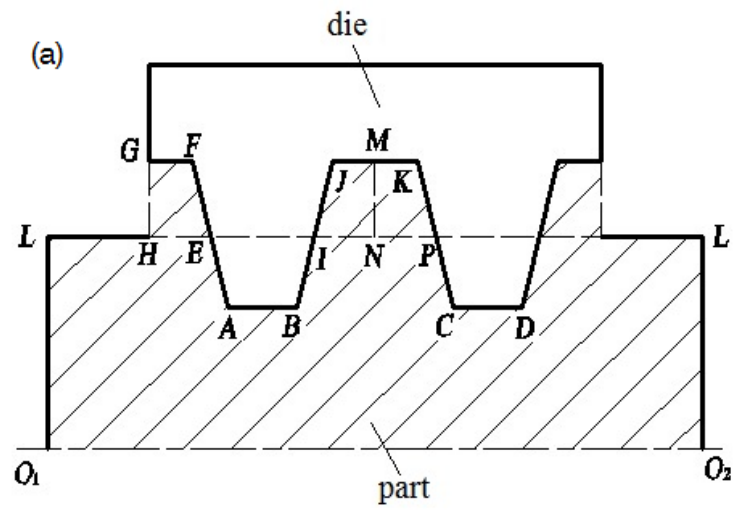

(a) Initial forming stage

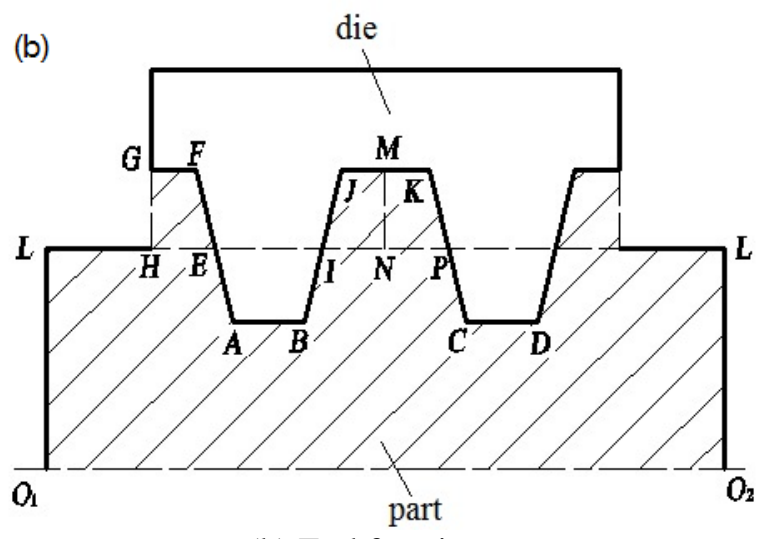

(b) End forming stage

Fig.2. Forming process of the teeth

In Figure 2(b), the end gullet of the die EFGH is the open structure towards the outside of the die. Under the effect of tooth extrusion of the die, the metal in the position EABI flows into the internal gullet. Following the principle of the minimum resistance, the metal EABI forcibly flows under the force action of single tooth cavity, thus the tooth defects appear on the ends of the teeth. In Figure 3, the teeth on the end of the thread shaft have the characteristics of inadequate tooth, lower tooth height, inaccurate tooth position, and larger pitch. The end tooth finally is formed into the shape of AQRT, which is not fully fit in the tooth gullet of the die, so the theoretical structure of AEFGRQA is replaced by the shape of RTH. When forming the thread shaft by cross wedge rolling, rolled part needs to rotate 3 to 4 cycles in the die cavity. Due to there is the deviation between the end position of the part and the tooth position of the die, the teeth of the die will squeeze the part in the form of a certain deviation when tooth deformation zone contact with the die in each rolling cycle, eventually tooth ends appear incomplete. Figure 4 shows a thread shaft formed by the FEM, since the teeth of the die can not exactly contact with the gullet of the rolled part, so the die has squeezed the teeth 
formed, and the teeth in the positions of $\mathrm{A}$ and $\mathrm{D}$ are incomplete. While, the final teeth in the positions of $\mathrm{B}$ and $\mathrm{C}$ are also not full, since the rolled tooth surfaces are not properly fit to the die tooth surfaces because of the larger pitch.

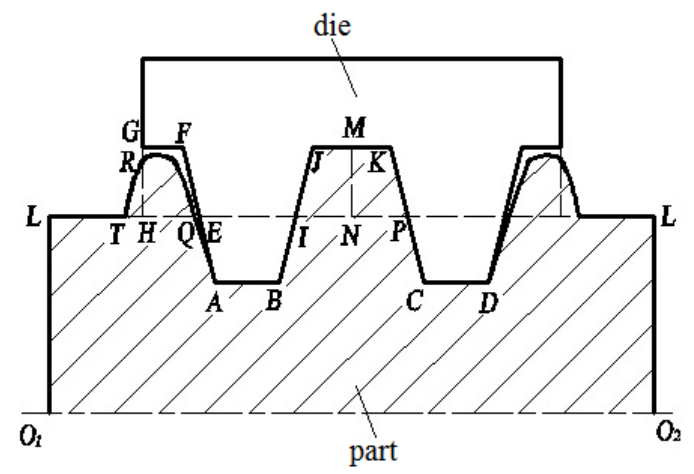

Fig.3. Tooth defects on the end of the part

\section{Solution of tooth defects on the end of the part}

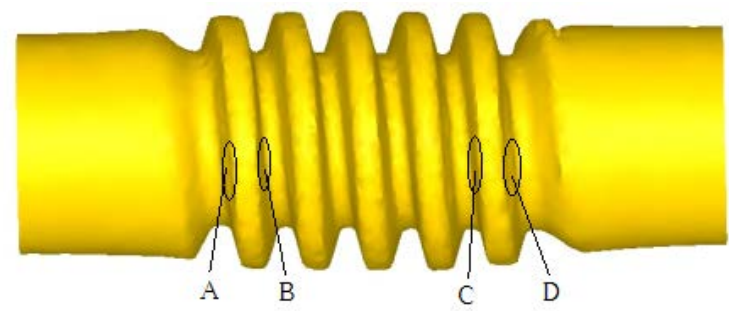

Fig.4. Thread shaft in EFM

The defects of incomplete teeth, low tooth height and large pitch always produce due to the open tooth structure of the die towards the outside of the die. Therefore, a method of solving the above defects is optimizing die structure, that is, the tooth structure is designed into closed cavity structure instead of open structure. The closed structure can effectively restrict the flow of the metal, eventually a complete tooth is formed, and the defects of tooth height and pitch significantly reduce. Figure 5 shows the thread simulated by FEM on the condition of the closed tooth structure of the die. When the closed die structure is used, the area between HK is tooth segments, the block of HRST is designed on the end of $\mathrm{H}$, and the same closed block on the end of $\mathrm{K}$. The die block is across the outer entire forming section, and a small gap between the end of HT and the contour line LL of the part is left. The HRST structure can ensure the exact teeth by restricting the flow of the metal. While the small gap between HT and LL can avoid the die completely contacting with the surface of the part, hindering normal rotation of the part, and influencing the forming of the part.

A finite element model is created according to the die shown in Figure 5, and complete forming process is simulated, finally the part is shown in Figure 6. Figure 6 shows the end tooth structure of the part is intact, the tooth height error and pitch error reduce, and the forming quality of the teeth improves. In addition, by adjusting other parameters of the die, the forming quality of the thread may also be appropriate to improve. For example a suitable helix angle trajectory of the die is designed, the axial component of forming region forced by die cavity reduces, and the amount of movement in the axial direction also reduces, thus tooth defects reduce.

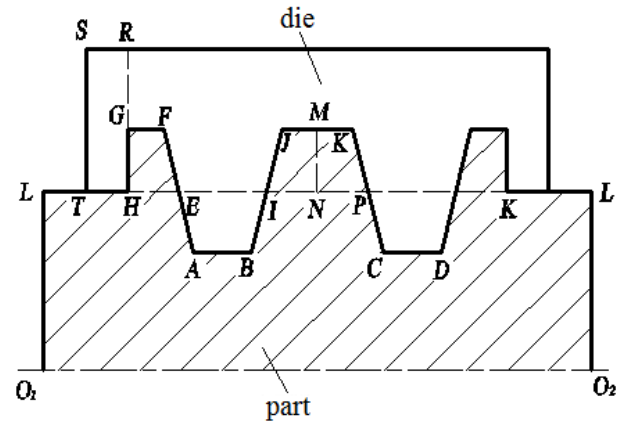

Fig.5. Improved Structure of the die

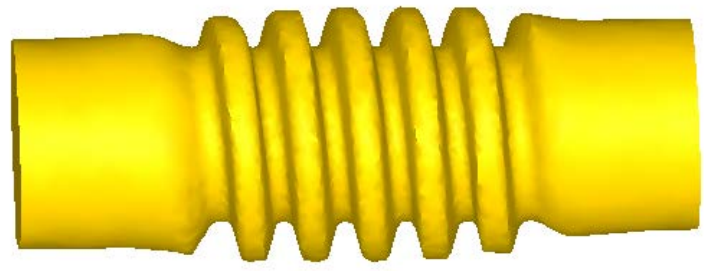

Fig.6. Rolled part by FEM

\section{Solution of the larger pitch on the end of the part}

The defect of larger pitch on the ends of the part is a big problem for thread shaft rolling by cross wedge rolling. In general, the tooth width of the die is designed by the equal width mode. Due to the plastic deformation of the metal under the role of the axial component, the thread width becomes large, thus the final tooth width is greater than the tooth width of the die. In order to ensure that the final tooth width is design value, taking into account the larger pitch in the process of plastic 
deformation of the thread, the initial tooth width needs to reduce, while the width gradually increases as the length increases, and the final tooth width increases to the theory width. Figure 7 shows the expansion diagram of the die, longitudinal boundary line for forming segment are AC and $\mathrm{BD}$, the initial tooth width of thread is $\mathrm{AB}, A B=W_{1}$, and the final width is $\mathrm{CD}, C D=W_{2}$. The initial width $W_{1}$ is less than the width $W$ designed for the die, thus tooth boundary line AC becomes a bias with small diagonal along the longitudinal direction $\mathrm{MN}$ of the die. But the initial tooth width can not be designed to be very small value. When the initial width of the die is too small, the end teeth or gullets will not be complete on the initial position, so that the die and the part can not consistently match, and the forming quality of teeth is seriously affected.

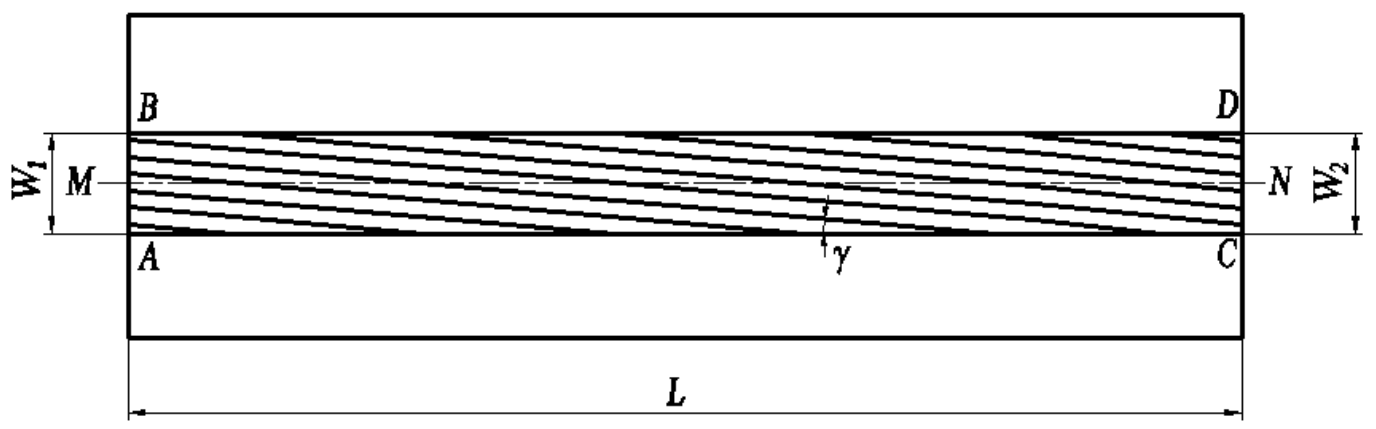

Fig.7. Expansion diagram of the die

In order to analyze the effect of the tooth width on the forming of the thread tooth, width parameter conditions are shown in Table 2. The finite element simulations for each process condition are made, the influence of tooth width on the tooth shape is researched by analyzing the pitches and the teeth shape. Research results shows that from condition 1 to condition 4, tooth width of the part gradually decreases as initial tooth width of the die increases, the width of the part increases the minimum amount in condition 3; from working condition 5 to condition 6 , the tooth width of the part does not continue to decrease, and the tooth shape on the end of the part appears incomplete. The initial tooth width in working conditions 3 should be selected to control the more exact tooth width and obtain better tooth quality.

Table 2 Parameters of the thread shaft

\begin{tabular}{cccc}
\hline No. & $\begin{array}{c}\text { Initial tooth width } \\
W_{1} / \mathrm{mm}\end{array}$ & $\begin{array}{c}\text { Final tooth width } \\
W_{2} / \mathrm{mm}\end{array}$ & $\begin{array}{c}\text { Length of the die } \\
\mathrm{L} / \mathrm{mm}\end{array}$ \\
\hline Condition 1 & 70.8 & & \\
Condition 2 & 69.8 & & \\
Condition 3 & 68.8 & 70.8 & 450 \\
Condition 4 & 67.8 & & \\
Condition 5 & 66.8 & & \\
\hline
\end{tabular}

\section{Conclusion}

When trapezoidal tooth thread shaft is formed, the defects of incomplete teeth, low tooth height and larger pitch appear on the both tooth ends of the part. The end tooth structure of the die is optimized into the closed structure instead of the open structure, thus the flow of the metal can be effectively controlled, and forming quality of tooth increases.

The tooth width of the die has a greater impact on the tooth width of the part. When the tooth width of the die is designed, the tooth width on the end of the final segment is designed to theoretical width, and the initial tooth width is less than the theoretical width, and ultimately by comparative analysis of 5 tooth width conditions, the high quality part is obtained and the desired the initial width is selected. 


\section{Acknowledgements}

In this paper, the research was sponsored by the Natural Science Foundation of Shijiazhuang Science and Technology Department (Project No. 141081321A), and the School Established Research Foundation of Hebei University of Science and Technology (Project No. TY16).

\section{References}

[1] Zhenghuan $\mathrm{Hu}$, Lin Hua: Forming technology of part rolling, edtied by Chemical Industry Press, Beijing, (2010), in press.

[2] Zhenhua Zheng, Baoyu Wang, Zhenghuan Hu: Mechanism of camshaft forming by cross wedge rolling, J Univ Sci Technol Beijing, Vol.32 (Issue 5) (2010), p. 650.

[3] Guang Yang. Study on rolling the driven rotor of the screw compressor. Beijing: School of Mechanical Engineering University of Science and Technology Beijing, 2015 (in Chinese)

[4] Jie Yu, Baoyu Wang: Teeth shape analysis of shaft teeth tormed by rolling. Forging \& Stamping Technology, Vol.37 (Issue 1) (2012), p. 76.

[5] Huajun Yan, Jinping Liu, Zhenghuan Hu, et al: Forming mechanism of trapezoidal thread shafts in cross wedge rolling. Journal of University of Science and Technology Beijing, Vol.34 (Issue 6) (2012), p. 701.

[6] Wenfei Peng, Jianhua Zhang, Wenjing Yu. High - temperature plastic deformation behavior of high- speed rail screw spike steel TD16. Transactions of Materials and Heat Treatment, Vol.36 (Issue 8) (2015), p. 243.

[7] Huajun Yan, Jinping Liu, Zhenghuan $\mathrm{Hu}$, et al: Effects of process parameters on forming helical tooth shaft in cross wedge rolling.Journal of Central South University (Science and Technology), Vol.43 (Issue 6) (2012), p. 2114.

[8] Huajun Yan, Haoen Mao, Guochang Li, et al: Effect of blank shape and size on the forming quality of thread shaft rolling in cross wedge rolling. Advanced Materials Research, Vol. 853 (2014), p. 605. 